\title{
The Influence of Molecular Weight and Tacticity on Thermal, Morphological and Mechanical Properties of Ziegler - Natta Catalyzed Isotactic and Syndiotactic Polypropylene Blends
}

\author{
Ismael AMER ${ }^{1,2}$ *, Albert VAN REENEN ${ }^{2}$, Touhami MOKRANI ${ }^{1}$ \\ ${ }^{1}$ Department of Chemistry and Polymer Science, University of Stellenbosch, Private Bag X1, Matieland 7602, South \\ Africa \\ ${ }^{2}$ Department of Civil and Chemical Engineering, College of Science, Engineering and Technology, University of South \\ Africa, Private Bag X6, Florida 1710, Johannesburg, South Africa
}

cross'ref http://dx.doi.org/10.5755/j01.ms.22.3.9056

\section{Received 05 January 2015; accepted 17 May 2015}

\begin{abstract}
The thermal, morphological and mechanical properties of polypropylene blends as influenced by the molecular weight and tacticity were investigated. Polypropylene sample blends (50/50 wt.\%) were injection moulded into standard disks for morphological and mechanical tests. The thermal properties of the polypropylene blends were measured by differential scanning calorimetry (DSC), while the morphological and mechanical properties of specimens were investigated by means of optical microscope (OM), scanning electron microscopy (SEM), microhardness $(\mathrm{MH})$ and dynamic mechanical analysis (DMA). DSC results of the bulk crystallization of the various isotactic polypropylene blends showed one melting peak, which indicates that cocrystallization of the blends occurred. However, the crystallization behavior of the polymer blends was strongly affected by the configuration (tacticity) and molecular weight of the polypropylene polymers. In addition, the MH and DMA measurements showed that blends of two different isotactic polypropylenes presented $\mathrm{MH}$ and storage modulus values between the values of the respective two $\mathrm{MH}$ and storage modulus values of the homopolymer samples, which in turn, depended on the type and degree of the crystallinity of the blends. However, the presence of syndiotactic polypropylene in a blend with isotactic polypropylene leads to a decrease in the $\mathrm{MH}$ value of the isotactic polypropylene samples.

Keywords: mechanical property, molecular weight, morphological property, polypropylene blend, tacticity.
\end{abstract}

\section{INTRODUCTION}

Polypropylene is one of the most widely used commercial polymers today. Its good mechanical properties and low price results in the continuous growth of its production and the expansion of its market. Its continuously increasing application accelerates research in all correlated areas, including the preparation of isotactic polypropylene based composites and blends [1]. The mechanical and physical properties of polypropylene are affected by a number of factors. The mechanical properties of the majority of polypropylene polymers are, apart from the processing conditions, influenced by their rheological and crystallization behavior. The degree of crystallinity is considered to be the most significant property influencing the physical and mechanical properties of a polypropylene sample [2-4]. An increase in crystallinity is often associated with an increase in properties such as the stiffness or modulus of a sample, while other factors, such as the impact strength, generally decrease with increasing crystallinity. The effects of molecular weight $[5,6]$, molecular weight distribution [7] and tacticity $[8,9]$ on the crystallization have been investigated by several authors.

Polymer blends have received much attention for many decades. Their morphology, crystallinity, microstructure, melting and crystallization behavior are

\footnotetext{
* Corresponding author. Tel.: +27 (0) 116709382

E-mail address: ismaelamer77@yahoo.co.za (I. Amer)
}

strongly dependent on the blend components [10-12]. The preparation of polymer blends is an important way to modify the target properties of individual polymers according to the requirements of the applications. Isotactic polypropylene based blends have been widely studied $[13,14]$. Blends of isotactic polypropylene and syndiotactic polypropylene have also been widely studied due to the fact that syndiotactic polypropylene exhibits good mechanical and optical properties [15, 16]. This depends on the syndiotactic degree and the average molecular weight of the syndiotactic polymer in the blend. These blends of isotactic and syndiotactic polypropylenes can compete with polyethylene terephthalate (PET) and polyvinyl chloride (PVC) for packaging applications [15]. However, the morphology of the blends is widely influenced by the crystallization kinetics, and although crystallization of isotactic and syndiotactic polypropylene always occurs separately, phase separation cannot be observed by microscopy [15].

The aim of this study is to display the structureproperty relationships of isotactic and syndiotactic polypropylene blends. The effect of molecular weight on the thermal, morphological and mechanical properties of isotactic and syndiotactic polypropylenes has previously largely ignored in similar studies. This study investigating the effect of molecular weight and tacticity on the thermal, morphological and mechanical properties of isotactic and syndiotactic polypropylenes blends. The thermal, morphological and mechanical properties of different 
polypropylene blends were investigated by means of differential scanning calorimetry (DSC), optical microscope (OM), scanning electron microscopy (SEM), microhardness $(\mathrm{MH})$ and dynamic mechanical analysis (DMA) to demonstrate the effect of isotacticity and molecular weight on the properties of different polypropylene blends.

\section{EXPERIMENTAL}

\subsection{Materials}

Isotactic polypropylene polymers with different molecular weights and tacticities (indicated as PP1-PP10 in Table 1 and Table 2) were prepared in our lab using a suitable Ziegler-Natta catalyst. Propylene was obtained from Sigma-Aldrich and used without any purification. High purity argon and hydrogen were obtained from Afrox (South Africa). Toluene (Sigma-Aldrich) was dried by refluxing over sodium/benzophenone and then distilling under an inert gas atmosphere. Triethylaluminum (TEA) was obtained from Sigma-Aldrich. A commercial ZieglerNatta catalyst with 2.78 wt.\% Ti content was purchased from Star Chemicals \& Catalysts Co. (China). The external donor (ED), diphenyl dimethoxysilane (DPDMS) and methylphenyl dimethoxysilane (MPDMS) were obtained from Fluka and used as received. Potassium permanganate, phosphoric acid and sulphuric acid were obtained from Sigma-Aldrich. A commercial syndiotactic polypropylene sample (indicated as SPP in Table 1 and Table 2) was obtained from Sigma-Aldrich and was used as received.

\subsection{Polymerization procedure}

The polymerization reactions were carried out in a 350-ml stainless steel Parr autoclave with a gas inlet and pressure gauge. The reactor was loaded with the catalyst (43 mg, Ti content 2.78 wt.\%), TEA ( $2 \mathrm{mmol}$, Al/Ti mole ratio 80$)$ and $\mathrm{ED}(0.091 \mathrm{ml}$ in the case of DPDMS and $0.072 \mathrm{ml}$ in the case of MPDMS, Al/Si mole ratio 5) in toluene $(25 \mathrm{~mL})$. The catalyst solution was stirred for $5 \mathrm{~min}$ and then the propylene was added. The reactor was pressurized with hydrogen and stirred for $1 \mathrm{~h}$ at room temperature. The reaction was then quenched by the addition of $10 \% \mathrm{HCl} / \mathrm{MeOH}$ solution. The resulting polymer was filtered off, washed several times with methanol, and subsequently dried under vacuum at $80^{\circ} \mathrm{C}$ for $15 \mathrm{~h}$, to yield about $3-5 \mathrm{~g}$ of polypropylene as a white powder. Characterization data for all the samples are given in Table 1 .

\subsection{Preparation for morphological and mechanical tests}

Test specimens were injection moulded into standard disks for morphological and mechanical tests with a HAAKE MiniJet II injection moulder. The injection moulding temperature was $190^{\circ} \mathrm{C}$ and the injection pressure was 200 bar. The dimensions of the standard disks were $20.0 \mathrm{~mm}$ in diameter and $1.5 \mathrm{~mm}$ in thickness.

\subsection{Preparation of etching reagent}

Permanganic etching of polyolefins was used to prepare samples for studying the morphology. This technique has been used in several studies involving polyolefins [12]. Potassium permanganate (1 g) was dissolved in $100 \mathrm{~mL}$ of a concentrated solution of 33 vol.\% phosphoric acid and 67 vol.\% sulphuric acid. The solution was prepared by adding potassium permanganate very slowly to the beaker containing both acids, with rapid agitation. After adding all the potassium permanganate, the beaker was closed and the contents stirred until all the potassium permanganate was dissolved (giving a dark green purple solution). All polypropylene samples were etched at room temperature.

\subsection{Etching procedure}

Specimens from each polymer, with approximate dimensions of length $10 \mathrm{~mm}$, width $5 \mathrm{~mm}$ and thickness $1.5 \mathrm{~mm}$, were cut from the disks prepared by injection moulding. Each sample was immersed in about $10 \mathrm{~mL}$ of the etching reagent in a beaker for a period of 60 minutes. This permanganic acid solution preferentially etches the amorphous part of the polymer in the spherulites in such a way that the lamellae then appear clearly. Subsequently, the specimens were carefully washed with hydrogen peroxide, distilled water and acetone, in order to avoid any artifacts caused by pollution effects. Samples were finally dried in a vacuum oven at $45^{\circ} \mathrm{C}$ for $5 \mathrm{~h}$.

\subsection{Methods}

The melting points and the degree of crystallinity were determined on a TA Instruments Q100 DSC. Three cycles were performed for each sample. The samples were heated in crimped aluminum pans from $-30{ }^{\circ} \mathrm{C}$ to $220{ }^{\circ} \mathrm{C}$ at a rate of $10^{\circ} \mathrm{C} / \mathrm{min}$. Samples were then cooled from $220^{\circ} \mathrm{C}$ to $-30^{\circ} \mathrm{C}$. Finally, the samples were heated for a second time at a rate of $10{ }^{\circ} \mathrm{C} / \mathrm{min}$ to $220^{\circ} \mathrm{C}$. This was done to determine the peak melting temperature, $\mathrm{T}_{\mathrm{m}}$, from the peak maximum of the second heating cycle.

Weight average molecular weight and molecular weight distribution (MWD) were obtained by hightemperature gel permeation chromatography (HT-GPC). Samples were analyzed with a PL-GPC 220, using a flow rate of $1.0 \mathrm{~mL} / \mathrm{min}$ and a differential refractive index (RI) detector. The analyses were carried out in 1,2,4trichlorobenzene (TCB) stabilized with $0.0125 \%$ 2,6-di-tert-butyl-4-methylphenol at $140{ }^{\circ} \mathrm{C}$. The calibration was done with monodisperse polystyrene standards (EasiCal from Polymer Laboratories).

Nuclear magnetic resonance analysis $\left({ }^{13} \mathrm{C}\right.$ NMR) spectra were recorded at $120^{\circ} \mathrm{C}$ on a 600 Varian Unity Inova NMR spectrometer equipped with an Oxford magnet (14.09 T), operating at $600 \mathrm{MHz}$, using a $5 \mathrm{~mm}$ inverse detection PFG probe. Samples $(60-80 \mathrm{mg})$ for ${ }^{13} \mathrm{C}$ NMR analyses were dissolved at $110{ }^{\circ} \mathrm{C}$ in a 9:1 mixture of TCB and benzene- $\mathrm{d}_{6}\left(\mathrm{Bz}_{6}\right)$.

A Zeiss Axiolab OM (magnification x 50-100 $\mu \mathrm{m}$ ) with a high resolution camera, CCD-IRIS (Sony), was used to examine the etched disks and investigate the crystal structure at room temperature under reflective light conditions. The disks of different polypropylene polymers used for OM test were obtained using a HAAKE MiniJet II injection moulder at $190{ }^{\circ} \mathrm{C}$ and 200 bar.

SEM analysis of etched disks was performed using a Leo® $1430 \mathrm{VP}$ scanning electron microscope operated at 
$15 \mathrm{kV}$ of acceleration voltage at room temperature. All the surfaces to be studied were coated with gold under vacuum in order to eliminate any undesirable charge effects during the SEM observations.

Samples for compressive DMA were analyzed using a Perkin Elmer DMA 7e calibrated according to standard procedures. The samples were first melted at $180{ }^{\circ} \mathrm{C}$ for 8 minutes and then melt pressed at $180{ }^{\circ} \mathrm{C}$ and $5 \mathrm{MPa}$ pressure. The samples were analyzed using a $5^{\circ} \mathrm{C} / \mathrm{min}$ heating ramp with an applied force oscillating at a frequency of $1 \mathrm{~Hz}$. The static force was kept constant at $110 \%$ of the dynamic force. The temperature range analyzed was between $-40{ }^{\circ} \mathrm{C}$ and $230{ }^{\circ} \mathrm{C}$.

MH measurements were conducted on a UHL microhardness tester equipped with a Vickers indenter. Measurements were obtained using an indentation speed of $25 \mu \mathrm{m} / \mathrm{s}$ and a dwell time of $15 \mathrm{~s}$. Samples were analyzed at indentation loads of $10 \mathrm{gf}$. Ten measurements were recorded for each sample analyzed.

\section{RESULTS AND DISCUSSION}

\subsection{Thermal properties}

The thermal properties of polymer blends are a strong function of the blend morphology. This morphology and the associated phase behaviour strongly depend on the cocrystallization between the components of the blend. Blending also allows us to determine the effect of the molecular weight and tacticity on the crystallinity of the new materials. The manner in which materials crystallize affects the morphology, which has a significant effect on the properties of the material.

\subsubsection{Effect of molecular weight}

Table 1 presents data for the individual polypropylene polymers as well as data for the blended polymers. The polymers (PP7 and PP8) and (PP7/PP8) blend (50:50 wt.\%) given in Table 1 were selected based on their differences in molecular weight and similarities in tacticity. DSC scans of individual polymer samples PP7 and PP8, and their blend (PP7/PP8) are presented in Fig. 1.

The blend showed only one melting peak (although the melting temperature is lower than that of the higher molecular weight material), even though the polypropylene sample PP7 has two melting peaks. This indicates that cocrystallization of the blend probably occurred. However, although a single melting peak of a blend is usually associated with a high extent of cocrystallization, two broad overlapping distributions of thicknesses of separate crystals, one from each component, could also lead to single broad peaks $[17,18]$. In addition, results from other studies indicated that the linear growth rate of crystals markedly decreases with increasing molecular weight [6], but the overall crystallization rate might increase because an increasing number of intramolecular folded-chain nuclei could result in a higher nucleation density [19]. The above results, however, indicate that molecular weight above $10000 \mathrm{~g} / \mathrm{mol}$ appears to play role in the crystallization of this blend in the bulk. In a previous study, Wild et al. found that the molecular weight only has an effect on crystallization of polypropylene at low molecular weights $(<10000 \mathrm{~g} / \mathrm{mol})$ [20].

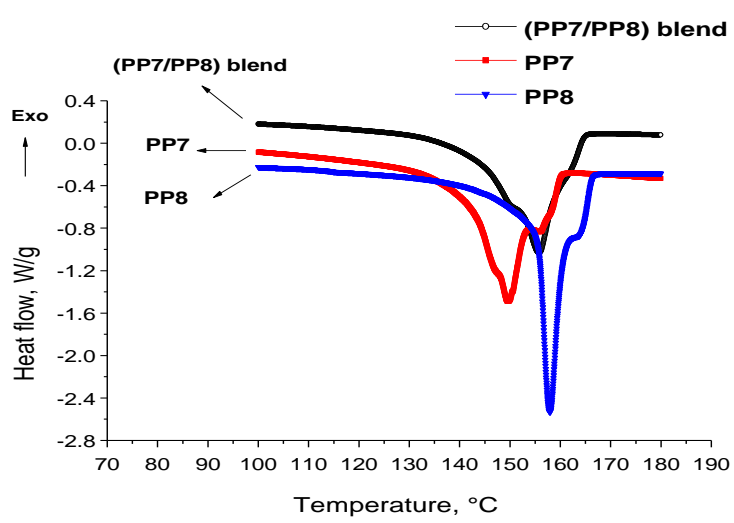

Fig. 1. DSC thermogram of a blend of selected polymers with the same tacticity but different molecular weights produced using heterogeneous catalysts

\subsubsection{Effect of isotacticity}

Fig. 2 shows the DSC scan of a blend of two polymer samples (PP6 and PP7) selected based on the differences in their tacticity and similarities in their molecular weight. The melting temperature of the (PP6/PP7) blend appeared to be influenced more by the material with the lowest tacticity (sample PP6 in Table 1 and Fig. 2).

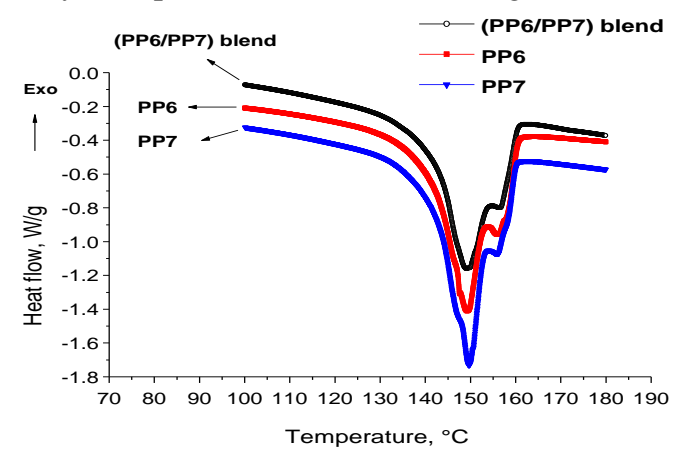

Fig. 2. DSC thermogram of a blend of selected polymers with similar molecular weights but different tacticities, produced using heterogeneous catalysts

Table 1. Characterization data of the polypropylene blends and fractions

\begin{tabular}{|c|c|c|c|c|c|c|}
\hline Samples & $\begin{array}{l}\mathrm{M}_{\mathrm{w}}{ }^{\mathrm{a}}, \\
\mathrm{g} / \mathrm{mol}\end{array}$ & MWD & $\begin{array}{c}\mathrm{mmmm}^{\mathrm{b}}, \\
\%\end{array}$ & $\mathrm{~T}_{\mathrm{m}},{ }^{\circ} \mathrm{C}$ & $\begin{array}{c}\Delta \mathrm{H}_{\mathrm{m}}, \\
\mathrm{J} / \mathrm{g}\end{array}$ & $\begin{array}{c}\mathrm{X}_{\mathrm{c}}, \\
\% \\
\end{array}$ \\
\hline PP1 & 252956 & 5.4 & 94.0 & 160.6 & 103.9 & 50.0 \\
\hline PP2 & 312580 & 4.1 & 96.0 & 161.9 & 108.9 & 52.0 \\
\hline PP3 & 215397 & 5.9 & 86.0 & 157.5 & 90.5 & 43.0 \\
\hline PP4 & 195693 & 4.3 & 98.0 & 160.0 & 119.7 & 57.0 \\
\hline PP5 & 207823 & 2.9 & 96.0 & 161.0 & 103.2 & 49.0 \\
\hline PP6 & 28270 & 2.4 & 84.0 & $148.9-158.7$ & 83.7 & 40.1 \\
\hline PP7 & 25918 & 2.4 & 93.0 & $149.5-158.3$ & 87.1 & 41.7 \\
\hline PP8 & 92596 & 3.5 & 93.0 & 157.9 & 110.1 & 52.7 \\
\hline $\begin{array}{c}\text { (PP4/PP5) } \\
\text { blend }\end{array}$ & - & - & - & 160.2 & 91.5 & 44.0 \\
\hline $\begin{array}{c}\text { (PP6/PP7) } \\
\text { blend }\end{array}$ & - & - & - & $148.5-158.7$ & 76.0 & 36.4 \\
\hline $\begin{array}{c}\text { (PP7/PP8) } \\
\text { blend }\end{array}$ & - & - & - & 155.8 & 96.1 & 46 \\
\hline SPP & 174000 & 2.3 & $93.0^{\mathrm{c}}$ & $111.9-126.5$ & 33.3 & 15.9 \\
\hline
\end{tabular}

These results are in agreement with previous results obtained by other studies [8-10]. They found that 
polypropylene blends with similar molecular weights and different tacticities showed an increase in linear crystal growth rate by three orders of magnitude when the isotacticity ( $\mathrm{mmmm} \%)$ of isotactic polypropylene increased from 78.7 to $98.8 \%[8,10]$.

The appearance of double peaks in the samples in Fig. 2 could be due to recrystallization processes [21, 22]. Recrystallization can usually be excluded by employing the DSC method with a wide range of heating rates, as shown in Fig. 3. The results in Fig. 3 show that the recrystallization occurs to a considerable degree only at heating rates lower than $10^{\circ} \mathrm{C} / \mathrm{min}$. For heating rates greater than $10^{\circ} \mathrm{C} / \mathrm{min}$ recrystallization on scanning does not have time to occur and determination of the effective $\Delta H_{m}$ and $T_{m}$ of the samples becomes possible. Although these are only preliminary results, indications are that there are two variables that influence cocrystallization in the bulk: molecular weight and tacticity. It is, however, not clear what the effect of the magnitude of the molecular weight (differences in molecular weight of individual components) and a variation in tacticity are. For better understanding of the recrystallization process, modulated DSC (MDSC) was used to analyze the (PP6/PP7) blend as shown in Fig. 4. The MDSC reversible (rev), nonreversible (nonrev) and total heat flow traces of the (PP6/PP7) blend can be seen in Fig. 4.

MDSC, in which a small sinusoidal oscillation (modulation) is superimposed on the conventional linear heating programme, is a useful thermal analysis technique to separate the total heat flow (such as that acquired from conventional DSC) into the heat capacity related (reversible) component and heat flow and kinetic (nonreversible) components [23]. The reversible heat flow is calculated by multiplication of the heat capacity with the negative heating rate. The kinetic component or nonreversible heat flow is the arithmetic difference between the total heat flow and the reversible heat flow. Thus, exothermic signals are detected only in the nonreversible data, but endothermic melting behavior can contribute to both reversible and nonreversible signals [24]. Hence, MDSC can separate exotherms (including crystallization and recrystallization) from glass transitions, reversible melting, or other heat capacity related events. The MDSC revealed the remarkable contribution of the technique in characterizing the broad recrystallization exotherms which showed how recrystallization controls the results. Because of offsetting exotherm and endothermic processes, the exotherm is barely detected by conventional DSC at different heating rates, as was reported previously by Lee and Porter [25], and many others [23, 24, 26]. However, using MDSC, as seen in Fig. 4, in the nonreversible heat flow curve, there is an exothermic peak followed by an endothermic peak. Since the nonreversible component is kinetic in nature and can be attributed to nonreversible melting and crystallization on heating, the existence of the processes of recrystallization and melting on heating was confirmed in the (PP6/PP7) blend. The reversible heat flow curve shows that double reverse melting peaks exist. The appearance of double melting peaks is due to the recrystallization processes. The endothermic peak in the nonreversible heat flow curve corresponds to the highest temperature endothermic peak in the curve for the reversible heat flow i.e. the two peaks in the reversible heat flow data correspond to the nonreversible and reversible components of the melting of recrystallized materials, respectively.

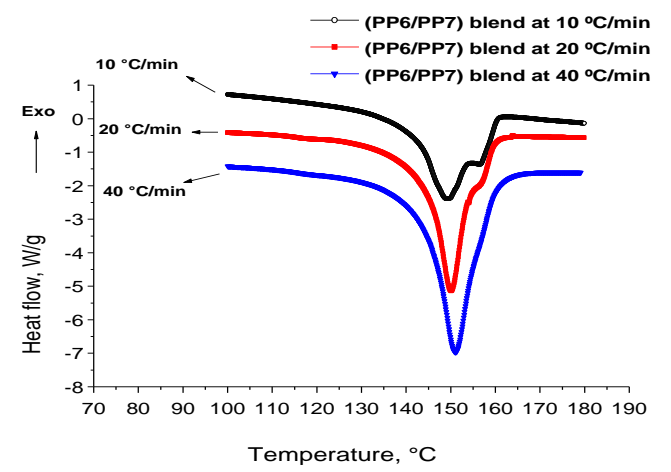

Fig. 3. DSC thermograms of the (PP6/PP7) blend at different heating rates

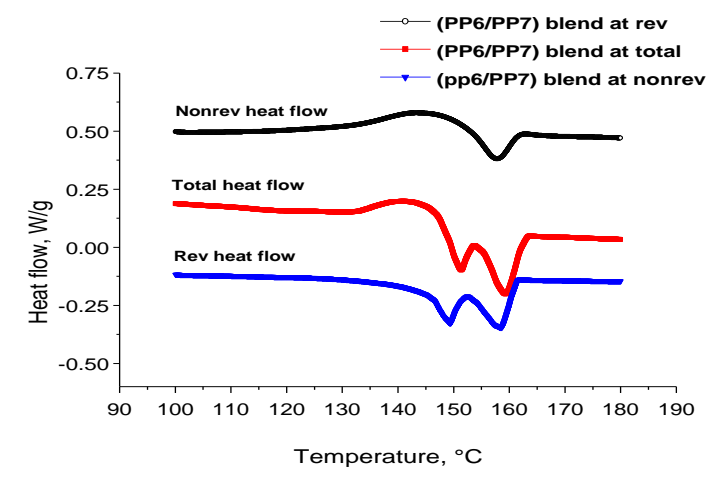

Fig. 4. MDSC heat flow curves of the (PP6/PP7) blend

Thus, the remaining reversible melting peak indicates the melting peak of the original crystals in the blend. This means that the PP6 and PP7 polypropylene polymers show a miscible blend.

\subsection{Morphological properties}

\subsubsection{Optical microscopy analysis}

Fig. 5 shows the OM micrographs of an isotactic polypropylene blend of the two isotactic polypropylene samples PP4 and PP5. As can be seen from Fig. 5, the (PP4/PP5) blend (Fig. 5 c) exhibited a large number of spherulitic crystals of isotactic polypropylenes crystallized from the melt [27]. The only slight difference between the polypropylene homopolymers and the blend are the size of the crystals and the manifestation of birefringence. These results indicate that the two isotactic polypropylene polymers are miscible.

Fig. 6 shows the OM micrographs of isotactic polypropylene PP2, syndiotactic polypropylene (SPP) and the isotactic/syndiotactic polypropylene blend, (PP2/SPP), respectively.

The syndiotactic polypropylene appeared as needlelike entities (Fig. 6 b), whereas spherulites were observed in the case of isotactic polypropylene (Fig. 6 a). The presence of syndiotactic polypropylene appeared to influence the growth and size of isotactic polypropylene spherulites in the (PP2/SPP) blend, resulting in a grainy crystal structure (Fig. 6 c). As observed in Fig. 6 c, for the (PP2/SPP) blend, isotactic polypropylene spherulites can hardly be seen, indicating a decrease in the crystal size. 


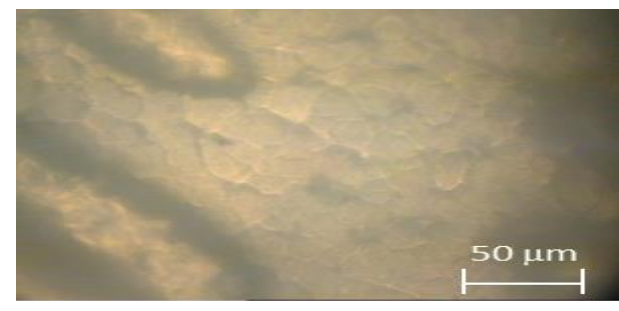

a

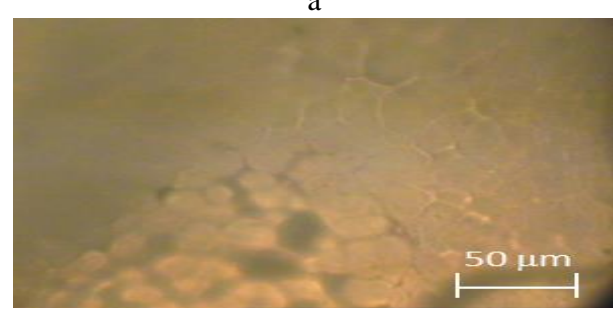

b

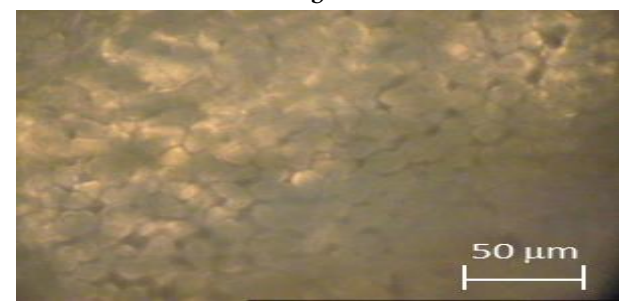

$\mathrm{c}$

Fig. 5. Optical micrographs of isotactic polypropylene samples and their blend: a-PP5; b-PP4; c-(PP4/PP5) blend (500x magnification)

The small and imperfect crystallites formed in the (PP2/SPP) blend are beneficial to promote the elasticity of isotactic/syndiotactic polypropylene blends $[15,16]$. Similar results were reported in a number of articles $[11,15,16,28]$.

\subsubsection{Scanning electron microscopy analysis}

Fig. $7 \mathrm{c}$ shows the SEM micrograph of an isotactic polypropylene blend of the two isotactic polypropylene samples PP5 and PP4 (Fig. $7 \mathrm{a}$ and b). All these isotactic polypropylenes revealed well-defined and large spherulitic morphology. In contrast to the OM results, clear differences were distinguished between the isotactic polypropylene samples shown in Fig. 7. These differences exist in the variety of spherulite sizes and spherulite types classified by their appearance, including the sign and nature of birefringence and crystal lattice. The average diameter of PP5 spherulites was about 5-15 $\mu \mathrm{m}$ (Fig. 7 a), whereas smaller dominant $\alpha$ spherulites (about 5-10 $\mu \mathrm{m}$ ) were observed for PP4 and the (PP4/PP5) blend (Fig. $7 \mathrm{~b}$ and $\mathrm{c}$ respectively). The sign and nature of birefringence and crystal lattice of the $\alpha$-spherulites of the (PP4/PP5) blend could also be clearly observed to be similar to those of the polypropylene sample with higher molecular weight as illustrated in Fig. 7 .

Also, the (PP4/PP5) blend had the same type of $\alpha$-modification spherulite structure of isotactic polypropylenes, which indicates that the two isotactic polypropylene samples PP4 and PP5 are miscible polymers [29, 30]. Fig. $8 \mathrm{c}$ shows the SEM micrograph of the blend (PP2/SPP) of isotactic polypropylene sample PP2 (Fig. 8 a) and syndiotactic polypropylene sample SPP (Fig. 8 c).

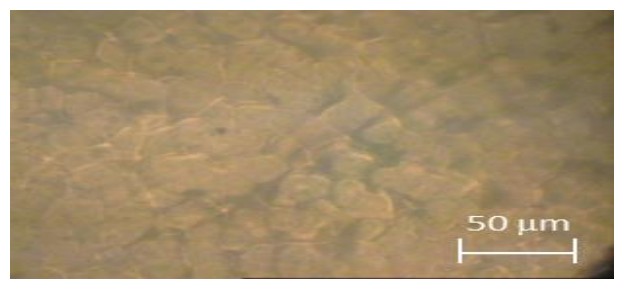

a

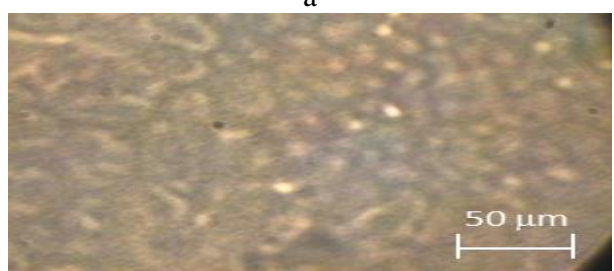

b

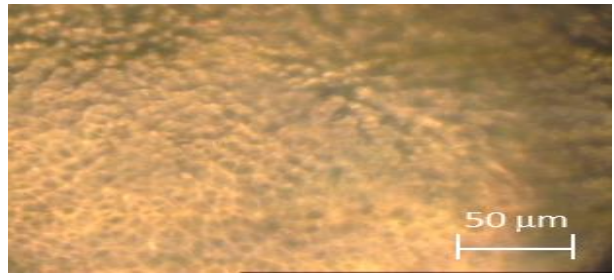

c

Fig. 6. Optical micrographs of: a-isotactic polypropylene PP2; $\mathrm{b}$-syndiotactic polypropylene SPP; $\mathrm{c}-(\mathrm{PP} 2 / \mathrm{SPP})$ blend (magnification: $5 \times 102$ )

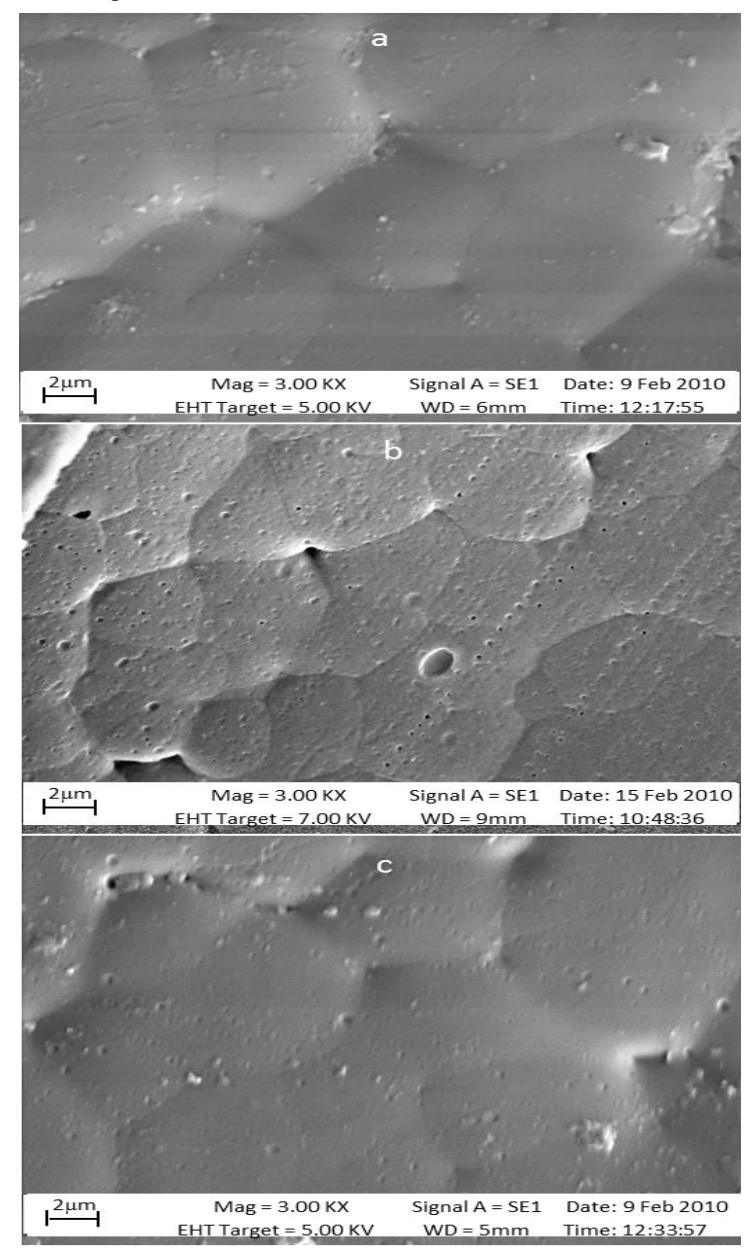

Fig. 7. SEM micrographs of isotactic polypropylene polymers and their blend: a-PP5; b-PP4; c-(PP4/PP5) blend (3000x magnification) 


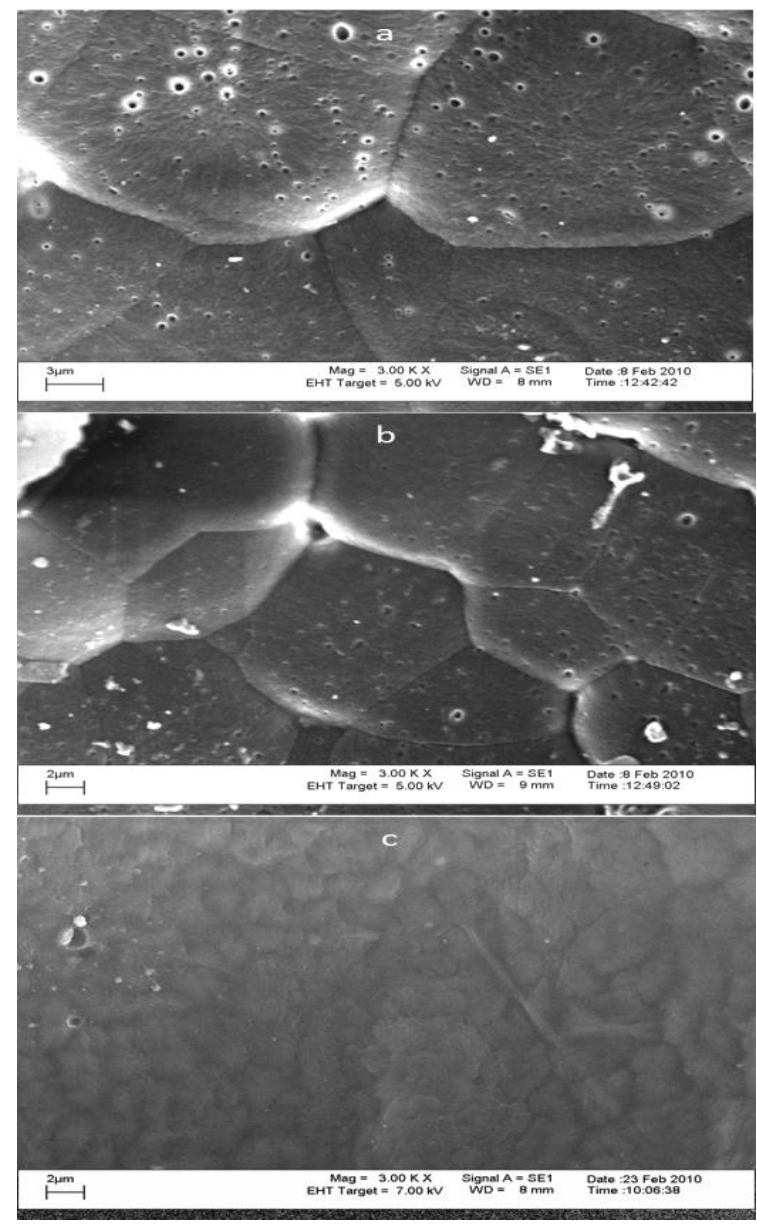

Fig. 8. SEM micrographs of: a-PP2; b-SPP; $c-($ PP2/SPP) blend (3000x magnification)

Similar to what was observed with the OM results (Fig. 6 c); SEM micrographs of the (PP2/SPP) blend displayed a grainy crystal structure. This indicates that the presence of syndiotactic polypropylene influences the growth and the size of isotactic polypropylene spherulites, which leads to less perfect spherulites. Similar results were obtained by Thomman et al. [31] and Bourbigot et al. [32]. They found that isotactic and syndiotactic polypropylene blends are phase separated and that crystallization of isotactic and syndiotactic polypropylenes in the blend occurs separately. They also found that crystallization of isotactic and syndiotactic polypropylene blends is dependent on the crystallization nature of the individual components. The SEM micrograph (Fig. 8 a) also displayed small dimples on the etched surface of PP2 sample, which sometimes grew to craters and holes. This was the result of the extractions of the rubbery materials by the etchant solution [33-36].

\subsection{Mechanical properties}

In order to correlate the structure of the polypropylene blends with the mechanical properties, the samples were analyzed using microhardness and DMA.

\subsubsection{Microhardness}

According to literature [37-42], all the parameters that lead to an increase of crystallinity and crystallite sizes (lamellar thickness) will also lead to higher $\mathrm{MH}$ values. Hence, the higher the isotacticity, the greater the $\mathrm{MH}$ values obtained.

The results of the $\mathrm{MH}$ of different polypropylene blends (50/50 wt.\%) are shown in Table 2. According to Flores et al. [40], $\mathrm{MH}$ of a polymer blend can be described in terms of an additive system of two independent components, as illustrated in the Eq. 1 below.

$\mathrm{MH}_{\mathrm{b}}=\mathrm{MH}_{1} \phi+\mathrm{MH}_{2}(1-\phi)$,

where $\mathrm{MH}_{\mathrm{b}}$ is the hardness of the blend, $\mathrm{MH}_{1}$ and $\mathrm{MH}_{2}$ are the hardness values of the single components, and $\phi$ is the weight fraction of component 1 . However, deviations from this equation may occur, depending on the variation in crystallinity of each phase in the blend. As can be seen in Table 2, the blends of the two different isotactic polypropylenes (PP9/PP10) and (PP1/PP3), have MH values between the values of the two homopolymers, which depend on the type and degree of the crystallinity of the blends.

It is reasonable that the higher isotacticity content in the blend allows easier recrystallization upon the application of an external force to the sample, thus improving the hardness of the sample upon indentation. This correspondence to results obtained by De Rosa et al [43]. They found that $\mathrm{MH}$ values increase with increasing isotacticity of polypropylene polymers.

It is also noteworthy that the syndiotactic polypropylene sample (SPP in Table 2) has a low MH value, due to its low degree of crystallinity and different type of crystals. The presence of syndiotactic polypropylene in the (PP2/SPP) blend led to a decrease in the $\mathrm{MH}$ value of the isotactic polypropylene sample PP2 (Table 2). This was due to a reduction in the growth and the size of isotactic polypropylene spherulites, which lead to less spherulite perfection, as can be observed in the OM and SEM results. These results agreed with the results obtained by Misheva et al. [44]. They showed that MH values decrease with the syndiotactic content of the studied syndiotactic polypropylene samples.

Table 2. MH results of different polypropylene blends (50/50 wt.\%)

\begin{tabular}{|c|c|c|c|c|c|}
\hline Sample & $\begin{array}{c}\text { Hardness, } \\
\text { HV 0.01 }\end{array}$ & $\begin{array}{c}m m m m, \\
\%\end{array}$ & $\begin{array}{c}\mathrm{M}_{\mathrm{w},} \\
\mathrm{g} / \mathrm{mol}\end{array}$ & MWD & $\begin{array}{c}\mathrm{X}_{\mathrm{c}}, \\
\%\end{array}$ \\
\hline PP9 & 7.5 & 93.0 & 184759 & 6.1 & 50.0 \\
\hline PP10 & 6.2 & 93.0 & 65498 & 8.2 & 48.0 \\
\hline (PP9/PP10) blend & 6.6 & - & - & - & 51.0 \\
\hline PP1 & 7.4 & 94.0 & 252956 & 5.4 & 50.0 \\
\hline PP3 & 6.1 & 86.0 & 215397 & 5.9 & 43.0 \\
\hline (PP1/PP3) blend & 6.3 & - & - & - & 44.0 \\
\hline PP2 & 7.7 & 96.0 & 271974 & 5.6 & 52.0 \\
\hline SPP & 4.2 & $93.0^{\mathrm{a}}$ & 174000 & 2.3 & 16.0 \\
\hline (PP2/SPP) blend & 4.8 & - & - & - & 36.2 \\
\hline${ }^{\mathrm{a}}$ Syndiotacticity $(\mathrm{rrrr} \%)$ & & & & \\
\hline
\end{tabular}

\subsubsection{Dynamic mechanical analysis}

Fig. 9 shows the storage modulus curves as a function of temperature for a 50/50 wt.\% (PP1/PP3) blend of the two isotactic polypropylene samples PP1 and PP3. Fig. 10 shows the storage modulus curves as a function of temperature for a 50/50 wt.\% (PP2/SPP) blend of isotactic and syndiotactic polypropylene samples. Over the full temperature range of the experiment, the storage modulus curve of the blend of the two isotactic polypropylenes was always between the storage modulus curves of the two isotactic homopolymers, which indicates that the two 
isotactic polymers are miscible.

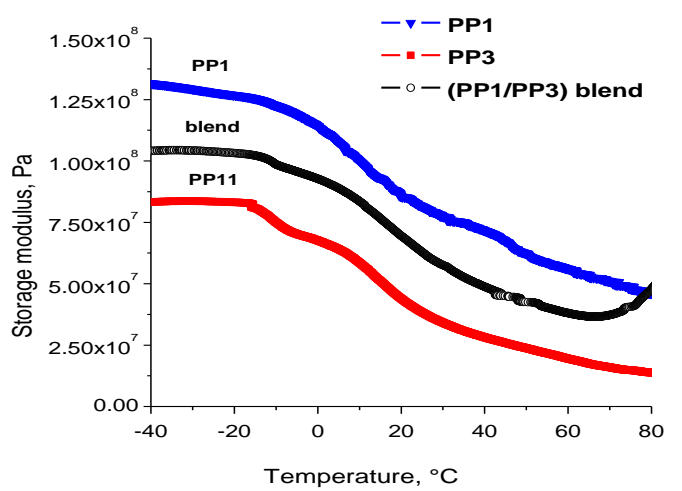

Fig. 9. Storage modulus values as a function of temperature for a 50/50 wt.\% (PP1/PP3) blend of two different isotactic polypropylene samples

However, the storage modulus curve of the isotactic/syndiotactic polypropylene blend (PP2/SPP) in Fig. 10 displayed different behaviour.

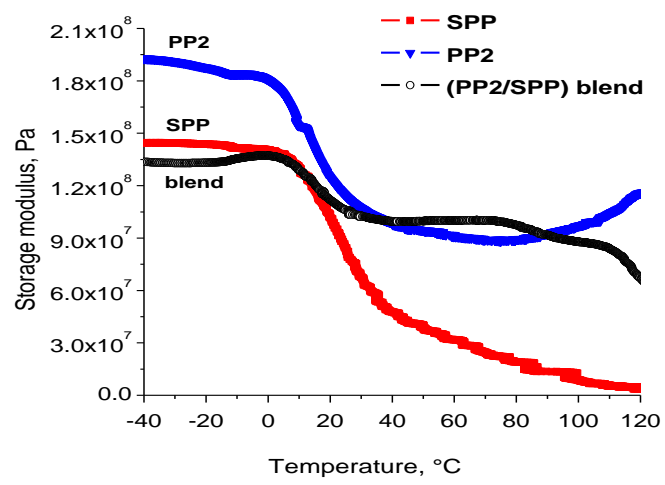

Fig. 10. Storage modulus values as a function of temperature for a 50/50 wt.\% (PP2/SPP) blend of isotactic and syndiotactic polypropylene samples

Within the temperature range of -40 to $10{ }^{\circ} \mathrm{C}$ (below the $\mathrm{T}_{\mathrm{g}}$ ), the (PP2/SPP) blend showed a lower storage modulus value than both PP2 and SPP homopolymers. Above $10{ }^{\circ} \mathrm{C}$, the storage modulus of the (PP2/SPP) blend increased above the storage modulus values of the syndiotactic polypropylene sample SPP. This could be due to the partial miscibility of the isotactic and syndiotactic polymers at temperatures higher than their glass temperatures. Our results are slightly different from the results obtained by Zhang et al. [45]. They found that within the temperature range from -25 to $0{ }^{\circ} \mathrm{C}$, the storage modulus values of syndiotactic polypropylenes decreased rapidly, while the storage modulus values of isotactic/syndiotactic polypropylene blends changes are much less significant than syndiotactic polypropylene. They also found that within the whole temperature range of the experiment, the storage modulus values of the blends are always lower than isotactic polypropylene samples, except for isotactic/syndiotactic polypropylene (90/10) blend, in which the highest storage modulus values were obtained. They attributed the high storage modulus values for isotactic/syndiotactic polypropylene blend (90/10) to the miscibility of isotactic/syndiotactic polypropylene (90/10) blend.
Generally, and as shown above in the OM and SEM results, the addition of syndiotactic polypropylene markedly affects the isotactic polypropylene spherulites and creates defects in the isotactic polypropylene crystals. This results in a decrease in the crystallinity of the blends, leading to a decrease of storage modulus values for the isotactic/syndiotactic polypropylene blends.

\section{CONCLUSIONS}

The effect of isotacticity and molecular weight on the thermal, morphological and mechanical properties of different polypropylene blends was investigated. The major factors affecting the structure and properties of polypropylene blends are those that lead to an increase of crystallinity. DSC and MH results indicated that the thermal and mechanical properties of polypropylene blends are considerably affected, not only by the tacticity, but also by the molecular weight of the polypropylenes. Furthermore, DSC, OM, SEM, MH and DMA indicated that blends of two different isotactic polypropylene samples are good miscible polymers. Whereas blends of isotactic and syndiotactic polypropylene samples are immiscible polymers, which lead to a decrease in the $\mathrm{MH}$ and storage modulus values of the isotactic/syndiotactic polypropylene blends.

\section{Acknowledgements}

The authors would like to thank 1) the International Centre of Macromolecules and Materials Science (Libya) for financial support for Ismael Amer and 2) Mrs Sonja Brandt for the English editing.

\section{REFERENCES}

1. Moore, Jr.E.P., Larson, G.A. Introduction to PP Business, Polypropylene Handbook. Munich: Hanser Publishers, 1996: pp. $257-285$.

2. Lima, M.F.S., $\quad$ Vasconcellos, M.A., Samios, D. Crystallinity Changes in Plastically Deformed Isotactic Polypropylene Evaluated by X-Ray Diffraction and Differential Scanning Calorimetry Methods Journal of Polymer Science Part B: Polymer Physics 40 (9) 2002: pp. 896-903.

3. Kang, J., Chen, Z., Chen, J., Yang, F., Weng, G., Cao, Y., Xiang, M. Crystallization and Melting Behaviors of the $\beta$ Nucleated Isotactic Polypropylene with Different Melt Structures - The Role of Molecular Weight Thermochimica Acta 599 2015: pp. 42-51.

4. Zhang, Y., Chen, H., Liu, B., Gu, Y., Li, X. Isothermal and Non-isothermal Crystallization of Isotactic Polypropylene Nucleated with 1,3,5-Benzenetricarboxylic Acid Tris(cyclohexylamide) Thermochimica Acta 590 2014: pp. $226-231$. http://dx.doi.org/10.1016/j.tca.2014.07.007

5. De Carvalho, B., Bretas, R.E. Quiescent Crystallization Kinetics and Morphology of Isotactic Polypropylene Resins for Injection Molding. I. Isothermal Crystallization Journal of Applied Polymer Science 68 (7) 1998: pp. 1159-1176. http://dx.doi.org/10.1002/(SICI)10974628(19980516)68:7<1159::AID-APP13>3.0.CO;2-T

6. Stern, C., Frick, A., Weickert, G. Relationship between the Structure and Mechanical Properties of Polypropylene: 
Effects of the Molecular Weight and Shear-induced Structure Journal of Applied Polymer Science 103 (1) 2007: pp. 519-533.

7. Phillips, P.J., Vatansever, N. Regime Transitions in Fractions of Cis-polyisoprene Macromolecules 20 (9) 1987: pp. $2138-2146$.

8. Janimak, J.J., Cheng, S.Z., Giusti, P.A., Hsieh, E.T. Isotacticity Effect on Crystallization and Melting in Polypropylene Fractions. II. Linear Crystal Growth Rate and Morphology Study Macromolecules 24 (9) 1991: pp. 2253-2260.

9. De Rosa, C., Auriemma, F. Structural-mechanical Phase Diagram of Isotactic Polypropylene Journal of the American Chemical Society $128(34)$ 2006: pp. 11024-11025.

10. Wang, Z.G., Phillips, R.A., Hsiao, B.S. Morphology Development During Isothermal Crystallization. I. Isotactic and Atactic Polypropylene Blends Journal of Polymer Science Part B: Polymer Physics 38 (19) 2000: pp. 2580-2590.

http://dx.doi.org/10.1002/1099-

0488(20001001)38:19<2580::AID-POLB100>3.0.CO;2-B

11. Wang, Z.G., Phillips, R.A., Hsiao, B.S. Morphology Development During Isothermal Crystallization. II. Isotactic and Syndiotactic Polypropylene Blends Journal of Polymer Science Part B: Polymer Physics 39 (16) 2001: pp. $1876-1888$. http://dx.doi.org/10.1002/polb.1162

12. Torre, J., Cortazar, M., Gomez, M., Ellis, G., Marco, C. Melting Behavior in Blends of Isotactic Polypropylene and a Liquid Crystalline Polymer Journal of Polymer Science Part B: Polymer Physics 42 (10) 2004: pp. 1949-1959.

13. Mohamad, N., Zainol, N.S., Maulod, H.E.A., $\quad$ Abd Rahim, T.,

Rahim, F.F., Shamsuri, S.R. Azam, M.A., $\quad$ Yaakub, M.Y., $\quad$ Abdollah, M.F.B., Manaf, M.E.A. Mechanical and Morphological Properties of Polypropylene/Epoxidized Natural Rubber Blends at Various Mixing Ratio Procedia Engineering 68 2013: pp. 439-445.

14. Madi, N.K. Thermal and Mechanical Properties of Injection Molded Recycled High Density Polyethylene Blends with Virgin Isotactic Polypropylene Materials \& Design 46 2013: pp. $435-441$.

15. Hill, M.J., Morgan, R.L., Barham, P.J. Minimum Branch Content for Detection of Liquid-liquid Phase Separation, Using Indirect Techniques, in Blends of Polyethylene with Ethylene-octene and Ethylene-butene Copolymers Polymer 38 (12) 1997: pp. 3003-3009.

16. Thomann, R., Kressler, J., Setz, S., Wang, C., Mülhaupt, R. Morphology and Phase Behaviour of Blends of Syndiotactic and Isotactic Polypropylene: 1. X-Ray Scattering, Light Microscopy, Atomic Force Microscopy, and Scanning Electron Microscopy Polymer 37 (13) 1996: pp. $2627-2634$.

17. Zhang, X., Zhao, Y., Wang, Z., Zheng, C., Dong, X., Su, Z. Morphology and Mechanical Behavior of Isotactic Polypropylene (iPP)/Syndiotactic Polypropylene (sPP) Blends and Fibers Polymer 46 (16) 2005: pp. 5956-5965. http://dx.doi.org/10.1016/j.polymer.2005.05.004

18. Amer, I., van Reenen, A. Fractionation and Crystallization of Isotactic Poly(propylenes) Prepared with a Heterogeneous Transition Metal Catalysts Macromolecular Symposia 282 (1) 2009: pp. 33-40.
19. Kim, M.H., Alamo, G.R., Lin, J.S., The Cocrystallization Behavior of Binary Blends of Isotactic Polypropylene and Propylene-ethylene Random Copolymers Polymer Engineering \& Science 39 (11) 1999: pp. 2117-2131.

20. Wild, L., Ryle, T.R., Knobeloch, D.C., Peat, I.R. Determination of Branching Distributions in Polyethylene and Ethylene Copolymers Journal of Polymer Science Part B: Polymer Physics 20 (3) 1982: pp. $441-455$.

21. Dudić, D., Kostoski, D., Djoković, V., Stojanović, Z. Recrystallization Processes Induced by Accelerated Ageing in Isotactic Polypropylene of Different Morphologies Polymer Degradation and Stability 67 (2) 2000: pp. 233-237.

22. Selikhova, V.I., $\quad$ Baranov, A.O., $\quad$ Zubov, Y.A., Bakeyev, N.F. Effect of Orientation and Annealing on Melting and Recrystallization Processes in Polypropylene Polymer Science USSR 31 (4) 1989: pp. 804-808.

23. Wang, X., Zhou, J., Li, L. Multiple Melting Behavior of Poly(butylene succinate) European Polymer Journal 43 (8) 2007: pp. $3163-3170$. http://dx.doi.org/10.1016/j.eurpolymj.2007.05.013

24. Sauer, B.B., Kampert, W.G., Blanchard, E.N., Threefoot, S.A., Hsiao, B.S. Temperature Modulated DSC Studies of Melting and Recrystallization in Polymers Exhibiting Multiple Endotherms Polymer 41 (3) 2000: pp. 1099-1108.

25. Lee, Y., Porter, R.S., Lin, J.S. On the Double-melting Behavior of Poly(ether ether ketone) Macromolecules 22 (4) 1989: pp. 1756-1760. http://dx.doi.org/10.1021/ma00194a043

26. Karger-Kocsis, J., Shang, P.P. A Modulated DSC Study on the Strain-induced $\beta \alpha$-Transformation in a $\beta$-Form Isotactic Polypropylene Journal of Thermal Analysis and Calorimetry 51 (1) 1998: pp. 237-244. http://dx.doi.org/10.1007/BF02719025

27. Lotz, B., Wittmann, J.C., Lovinger, A.J. Structure and Morphology of Poly(propylenes): a Molecular Analysis Polymer 37 (22) 1996: pp. 4979-4992.

28. Thomann, R., Kressler, J., Rudolf, B., Mulhaupt, R. Morphology and Phase Behaviour of Blends of Syndiotactic and Isotactic Polypropylene: 2. Differential Scanning Calorimetry, Light Transmission Measurements, and PVT Measurements Polymer 37 (13) 1996: pp. 2635-2640.

29. Park, J., Eom, K., Kwon, O., Woo, S. Chemical Etching Technique for the Investigation of Melt-crystallized Isotactic Polypropylene Spherulite and Lamellar Morphology by Scanning Electron Microscopy Microscopy and Microanalysis 7 (3) 2001: pp. 276-286.

30. Wang, J., Dou, Q. Crystallization Behaviors and Optical Properties of Isotactic Polypropylene: Comparative Study of a Trisamide and a Rosin-type Nucleating Agent Colloid \& Polymer Science 286 (6--7) 2008: pp. 699-705.

31. Thomann, R., Kressler, J., Setz, S., Wang, C., Mülhaupt, R. Morphology and Phase Behaviour of Blends of Syndiotactic and Isotactic Polypropylene: 1. X-Ray Scattering, Light Microscopy, Atomic Force Microscopy, and Scanning Electron Microscopy Polymer $37(13)$ 1996: pp. 2627-2634.

32. Bourbigot, S., Garnier, L., Revel, B., Duquesne, S. Characterization of the Morphology of iPP/sPP Blends with Various Compositions eXPRESS Polymer Letters 7 (3) 2013: pp. $224-237$. 
33. Freedman, A., Bassett, D.C., Vaughan, A., Olley, R.H. On Quantitative Permanganic Etching Polymer 27 (8) 1986: pp. $1163-1169$.

34. Shabana, H.M., Guo, W., Olley, R.H., Bassett, D.C. Electron Microscopic Observation of Spinodal Decomposition in Blends of Tetramethyl Polycarbonate and Polystyrene Polymer 34 (6) 1993: pp. 1313-1315.

35. Olley, R.H., Bassett, D.C. An Improved Permanganic Etchant for Polyolefines Polymer 23 (12) 1982: pp. 1707-1710.

36. Rybnikar, F. Selective Etching of Polyolefines. I. Isotactic Polypropylene Journal of Applied Polymer Science 30 (5) 1985: pp. 1949-1961.

37. Seidler, S., Koch, T. Determination of Local Mechanical Properties of $\alpha$ - and $\beta$ - PP by Means of Microhardness Measurements Journal of Macromolecular Science Part B Physics B41 (4-6) 2002: pp. 851-861.

38. Arranz-Andres, J., Pena, B., Benavente, R., Perez, E., Cerrada, M.L. Influence of Isotacticity and Molecular Weight on the Properties of Metallocenic Isotactic Polypropylene European Polymer Journal 43 (6) 2007: pp. 2357-2370.

39. Koch, T., Seidler, S., Halwax, E., Bernstorff, S. Microhardness of Quenched and Annealed Isotactic Polypropylene Journal of Materials Science $42(14)$ 2007: pp. $5318-5326$.

40. Flores, A., Aurrekoetxea, J., Gensler, R., Kausch, H.H., Calleja, F.J. Microhardness-structure Correlation of iPP/EPR Blends: Influence of Molecular Weight and EPR
Particle Content Colloid and Polymer Science 276 (9) 1998: pp. 786-793.

41. Harding, G.W., van Reenen, A.J. Polymerisation and Structure-property Relationships of Ziegler-Natta Catalysed Isotactic Polypropylenes European Polymer Journal 47 (1) 2011: pp. $70-77$.

42. Zhang, Z., Lei, J., Chen, Y., Chen, J., Ji, X., Tang, J. Tailored Structure and Properties of Injection-Molded Atactic Polypropylene/Isotactic Polypropylene Blend ACS Sustainable Chemistry \& Engineering 1 (8) 2013: pp. $937-949$.

43. De Rosa, C., Auriemma, F., Di Capua, A., Resconi, L., Guidotti, S., Camuratie, I. Structure-property Correlations in Polypropylene from Metallocene Catalysts: Stereodefective, Regioregular Isotactic Polypropylene Journal of the American Chemical Society 126 (51) 2004: pp. 17040-17049.

44. Misheva, M., Djourelov, N., Zamfirova, G., Gaydarov, V., Cerrada, M.L., Rodri'guez-Amor, V. Effect of Compatibilizer and Electron Irradiation on Freevolume and Microhardness of Syndiotactic Polypropylene/Clay Nanocomposites Radiation Physics and Chemistry 77 (2) 2008: pp. 138-145.

45. Zhang, X., Zhao, Y., Wang, Z., Zheng, C., Dong, X., Su, Z. Morphology and Mechanical Behavior of Isotactic Polypropylene (iPP)/Syndiotactic Polypropylene (sPP) Blends and Fibers Polymer 46 (16) 2005: pp. 5956-5965. 